\title{
Identification of differentially expressed genes in SHSY5Y cells exposed to okadaic acid by suppression subtractive hybridization
}

\author{
Vanessa Valdiglesias ${ }^{1,2}$, Juan Fernández-Tajes², Eduardo Pásaro ${ }^{1}$, Josefina Méndez ${ }^{2}$ and Blanca Laffon ${ }^{1 *}$
}

\begin{abstract}
Background: Okadaic acid (OA), a toxin produced by several dinoflagellate species is responsible for frequent food poisonings associated to shellfish consumption. Although several studies have documented the OA effects on different processes such as cell transformation, apoptosis, DNA repair or embryogenesis, the molecular mechanistic basis for these and other effects is not completely understood and the number of controversial data on OA is increasing in the literature.

Results: In this study, we used suppression subtractive hybridization in SHSY5Y cells to identify genes that are differentially expressed after OA exposure for different times (3,24 and $48 \mathrm{~h}$ ). A total of 247 subtracted clones which shared high homology with known genes were isolated. Among these, 5 specific genes associated with cytoskeleton and neurotransmission processes (NEFM, TUBB, SEPT7, SYT4 and NPY) were selected to confirm their expression levels by real-time PCR. Significant down-regulation of these genes was obtained at the short term (3 and $24 \mathrm{~h}$ OA exposure), excepting for NEFM, but their expression was similar to the controls at $48 \mathrm{~h}$.

Conclusions: From all the obtained genes, 114 genes were up-regulated and 133 were down-regulated. Based on the NCBI GenBank and Gene Ontology databases, most of these genes are involved in relevant cell functions such as metabolism, transport, translation, signal transduction and cell cycle. After quantitative PCR analysis, the observed underexpression of the selected genes could underlie the previously reported OA-induced cytoskeleton disruption, neurotransmission alterations and in vivo neurotoxic effects. The basal expression levels obtained at $48 \mathrm{~h}$ suggested that surviving cells were able to recover from OA-caused gene expression alterations.
\end{abstract}

\section{Background}

Okadaic acid $(\mathrm{OA})$ is a marine toxin produced by several dinoflagellate species. It was firstly isolated from the black sponge Halichondria okadai [1] and is frequently found in several types of molluscs usual in the human diet as those from Mytilus or Ostrea genus. The ingestion of OA-contaminated shellfish results in a syndrome known as diarrhoeic shellfish poisoning (DSP) which is characterized by severe gastrointestinal symptoms including nauseas, vomit, diarrhoea and abdominal ache [2]. Although fatalities associated with DSP-contaminated shellfish have not been reported, this intoxication

\footnotetext{
* Correspondence: blaffon@udc.es

${ }^{1}$ Toxicology Unit, Psychobiology Department, University of A Coruña, Edificio de Servicios Centrales de Investigación, Campus Elviña s/n, 15071 A Coruña, Spain

Full list of author information is available at the end of the article
}

has become a serious problem for public health and for the economy of aquaculture industries in several parts of the world [3].

OA was found to be a very potent tumour promoter in two-stage carcinogenesis experiments in vivo involving mouse skin [4] or mucosa of the rat glandular stomach [5]. OA was also reported to induce different genotoxic, cytotoxic, and embryotoxic effects such as micronuclei [6-8], oxidative DNA damage [9,10], DNA strand breaks and alterations in DNA repair [11], mitotic spindle alterations $[12,13]$, apoptosis $[14,15]$, cell cycle disruptions $[15,16]$, anomalies of the embryonic development [17] and teratogenicity [18]. Besides, despite the fact that DSP toxins are not classified as neurotoxins [19], some previous studies have already reported neurotoxic effects induced by $\mathrm{OA}$ including neuronal apoptosis and cytoskeleton alterations [20,21],
C Biomed Central

(c) 2012 Valdiglesias et al; licensee BioMed Central Ltd. This is an Open Access article distributed under the terms of the Creative Commons Attribution License (http://creativecommons.org/licenses/by/2.0), which permits unrestricted use, distribution, and reproduction in any medium, provided the original work is properly cited. 
deficits in spatial memory [22] and also cognitive deficits in rodents [23].

On the basis on these and other previous studies, OA represents other potential threats to human health besides DSP, even at concentrations within the nanomolar range. It is well-known that OA can inhibit specifically the serine/threonine protein phosphatases 1 (PP1) and 2A (PP2A) [24]; the number of physiological processes in which those phosphatases are involved is immense, including regulation of glycogen metabolism and coordination of the cell cycle and gene expression [25]. So this role of phosphatase inhibition by OA could explain most of the cell effects induced by this toxin [26]. However the number of controversial data in the literature continues increasing and further investigations on biochemical and molecular OA action mechanisms are required since the fact that non-phosphatase targets for OA are not known does not mean that they do not exist [3]. In fact, the existence of OA binding proteins other than phosphatases was demonstrated in several marine organisms $[27,28]$.

In this study, a suppression subtractive hybridization (SSH) approach was used to identify genes differentially expressed in SHSY5Y cells in response to OA exposure at different times (3, 24 and $48 \mathrm{~h}$ ). Sequences obtained by SSH were used to search for homology/identity to nucleotide and protein databases. Furthermore, differential expression patterns of 5 selected genes were also studied in OA-treated SHSY5Y cells at 3, 24 and $48 \mathrm{~h}$ by real-time PCR.

\section{Methods}

Cell culture and $O A$ treatment

SHSY5Y cells (human neuroblastoma cell line) were obtained from the European Collection of Cell Cultures and cultured in nutrient mixture EMEM/F12 (1:1) medium with $1 \%$ non-essential aminoacids, $1 \%$ antibiotic and antimycotic solution and supplemented with $10 \%$ heat-inactivated foetal bovine serum, all from Invitrogen (Barcelona, Spain). The cells were incubated in a humidified atmosphere with $5 \% \mathrm{CO}_{2}$ at $37^{\circ} \mathrm{C}$. OA (CAS No. 78111-17-8) was purchased from Sigma-Aldrich Co. (Madrid, Spain) and dissolved in DMSO prior use.

Flasks with approximately $90 \%$ of confluence and $4 \times$ $10^{6}$ cells were chosen for the experiments. For the treatments, cells were incubated at $37^{\circ} \mathrm{C}$ for 3,24 or $48 \mathrm{~h}$ in the presence of OA $(100 \mathrm{nM})$ or the control dimethylsulfoxide (DMSO) at $1 \%$ of final volume.

\section{Total RNA isolation and CDNA synthesis for SSH}

After OA treatments, total RNA was isolated from SHSY5Y cells with TRIZOL ${ }^{\circledR}$ reagent (Invitrogen, Madrid, Spain) following the manufacturer's instructions, and then dissolved in nuclease-free water. RNA was quantified and quality checked using the NANODROPTM 1000 spectrophotometer (Thermo Scientific, Madrid, Spain). One microgram of total RNA from each sample was used as template to synthesize the first strand cDNA with the SMART ${ }^{\mathrm{TM}}$ PCR cDNA Synthesis Kit (Clontech, Madrid, Spain), a method for producing high quality cDNA from a low amount of starting material [29]. The double stranded cDNA was amplified with the same Kit according to the manufacturer's protocol.

\section{Construction of subtracted CDNA libraries}

SSH was carried out with the PCR-Select ${ }^{\mathrm{TM}}$ CDNA subtraction kit (Clontech, Madrid, Spain), as described by the manufacturer. Briefly, the double stranded cDNAs obtained from the step described above were digested with the restriction enzyme RsaI to obtain blunt-ends that are necessary for adaptor ligation. cDNA subtraction was carried out in two directions for the different exposure times. The forward subtracted libraries were made with the control cells cultured for 3,24 or $48 \mathrm{~h}$ as the driver and OA-exposed cells (also cultured for 3, 24 or $48 \mathrm{~h}$ ) as the tester. These forward reaction libraries were designed to produce clones that are overexpressed or up-regulated in OA-treated cells. The reverse libraries were made in the same way, but in this case the adapter ligated cDNA from OA-exposed cells were the driver and control cells were the tester. The reverse reaction library was designed to produce clones underexpressed or down-regulated in OA-treated cells. In either case the driver cDNA was added in excess during each hybridization to remove common cDNAs by hybrid selection and leaving overexpressed and novel tester cDNA to be recovered and cloned. The subtracted cDNA fragments were then inserted into $y \mathrm{~T} \& \mathrm{~A}^{\circledR}$ cloning vector, transformed into Escherichia coli ECOS707 (strain JM109) competent cells, and plated on LB agar plates containing $100 \mu \mathrm{g} / \mathrm{ml}$ ampicillin, $100 \mu \mathrm{l}$ IPTG $(100 \mathrm{mM})$ and $20 \mu \mathrm{l} \mathrm{X}$-gal $(50 \mathrm{mg} / \mathrm{ml})$. The $\mathrm{yT} \& \mathrm{~A}^{\circledR}$ cloning vector and the E. coli ECOS707 competent cells were purchased from Yeastern Biotech. Co., Ltd., (Taipei, Taiwan). From the six libraries, a total of 384 white recombinant colonies (corresponding to four 96-well plates) were picked.

\section{Sequencing of the subtracted CDNA clones and bioinformatics analysis}

Sequencing of all the cDNA clones from the six SSH libraries was carried out using the BigDye ${ }^{\circledR}$ Terminator v3.1 (Applied Biosystems) and an AB3730 sequencer (Applied Biosystems) at Secugen (Madrid, Spain). After excluding redundant and false-positive sequences, nucleic acid homology searches were performed against nucleotide databases at the National Center for Biotechnology Information (NCBI) using the Basic Local 
Alignment Search Tool (BLASTX and BLASTN) http:// www.ncbi.nlm.nih.gov/BLAST to provide gene annotation. Homologies that showed identities over $60 \%$ and E-values of less than $1 \times E^{-10}$ with more than 100 nucleotides were considered to be significant. The differentially expressed genes identified through expression analysis were classified according to the definition of Gene Ontology (GO) http://www.geneontology.org/ related to the aspects of biological and molecular function.

\section{Differential screening of the subtracted libraries}

With the aim of checking the level of background corresponding to common mRNAs in reverse and forward libraries we carried out a differential screening of subtracted libraries using the PCR select differentially screening kit (Clontech, Madrid, Spain), following the manufacturer's instructions. Briefly, PCR products from positive colonies were immobilized in nylon membranes and hybridized with forward- and reverse- probes. Those clones representing mRNAs truly differentially expressed should hybridize only with its corresponding forward-probe. Prior to hybridization forward- and reverse-probes were digested for removing adaptors. More than $90 \%$ of the clones tested resulted positive for the virtual Northern analysis (data not shown).

\section{Simple gene set enrichment analysis}

A simple gene set enrichment analysis was performed using FatiGO tool (Babelomics 4.2 suite, http://babelomics.bioinfo.cipf.es/). FatiGO takes two lists of genes and convert them into two lists of GO annotations. Then a Fisher's exact test for $2 \times 2$ contingency tables is used to check for significant over-representation of GO annotations in one of the sets with respect to the other one. Multiple test correction is applied as a measure of control for false positives. In our case, we conducted two single gene set enrichment analysis for KEGG (Kyoto Encyclopedia of Genes and Genomes) pathways comparing our set genes from forward and reverse libraries with the rest of annotations in human genome (additional files 1 and 2).

\section{Quantitative PCR}

Five EST identified from SSH were chosen for their specific analysis with real-time PCR. First strand synthesis was performed on $100 \mathrm{ng}$ of the same total RNA samples prepared for SSH from OA-treated and control SHSY5Y cells (for 3, 24 and $48 \mathrm{~h}$ ) using the Transcriptor First Strand cDNA Synthesis Kit (Roche). Oligonucleotide primers were designed based on the EST sequences determined for candidate differentially expressed genes using the web tool Universal ProbeLibrary (Roche) (Table 1). Quantitative PCR was run in
Table 1 Primers used in real-time PCR analysis

\begin{tabular}{|c|c|c|}
\hline Genes & Primers $\left(5^{\prime}-3^{\prime}\right)$ & Product (bp) \\
\hline \multirow[t]{2}{*}{ NEFM } & TGCCGGCTACATAGAGAAGG & 62 \\
\hline & TCTCCGCCTCAATCTCCTTA & \\
\hline \multirow[t]{2}{*}{ TUBB } & CCCTCTGTGTAGTGGCCTIT & 68 \\
\hline & CCAGACAACTTTGTATTTGGTCA & \\
\hline \multirow[t]{2}{*}{ SEPT7 } & CACAATGTTCACCATTITCAAC & 82 \\
\hline & TCATTGAAGTTAATGGCAAAAGG & \\
\hline \multirow[t]{2}{*}{ SYT4 } & AAAGTTGTAAGGGGCCAATTC & 70 \\
\hline & ACCTCAGCTGCTACCACCAT & \\
\hline \multirow[t]{2}{*}{ NPY } & CGCTGCGACACTACATCAAC & 62 \\
\hline & CTCTGGGCTGGATCGTTT & \\
\hline \multirow[t]{2}{*}{ TPR } & CCACCGAGCGAGGTGATA & 67 \\
\hline & AGAAGAAAGGCGAAGACCAGT & \\
\hline \multirow[t]{2}{*}{ ACTB } & AAGTCCCTTGCCATCCTAAAA & 91 \\
\hline & ATGCTATCACCTCCCCTGTG & \\
\hline \multirow[t]{2}{*}{ NM23A } & ACATCCATTTCCССТССТTC & 92 \\
\hline & AGCTTCCCTCCAAACTATGATG & \\
\hline
\end{tabular}

triplicate using LightCycler ${ }^{\circledR}$ SYBR green I Master Kit (Roche) and LightCycler ${ }^{\circledR} 480$ Real-time PCR Detection System (Roche). The PCR conditions were $95^{\circ} \mathrm{C}$ for 10 $\mathrm{s}, 60^{\circ} \mathrm{C}$ for $10 \mathrm{~s}$, and $72^{\circ} \mathrm{C}$ for $5 \mathrm{~s}$, for 45 cycles, and final extension of $5 \mathrm{~min}$. A subsequent melting temperature curve of the amplicon was performed. Efficiency of target amplification was optimised prior to running samples for each of the five primer pairs by assaying four primer concentrations (200, 150, 100 and $50 \mathrm{nM}$ ). The number of amplification steps required to reach the threshold cycle number $(\mathrm{Ct})$ was computed using LightCycler software 1.5.0 (Roche). Constant Ct values were observed at a $100 \mathrm{nM}$ final primer concentration for each of the primer pairs. Ct values were calculated from the standard curve, entered into the qBasePlus software [30] and used to generate an input file for genNorm software v3.5 [31]. GenNorm determined the most stable reference genes out of the panel of candidate genes using expression stability analysis by pair wise correlations. Following the results of the genNorm, TPR, $\mathrm{ACTB}$ and NM23A genes were selected and run separately in all experiments under the same conditions. Normalised cDNA levels of each gene were calculated using qBasePlus [30] once the most stable reference genes were determined. The expression levels of each gene of the $3 \mathrm{~h}$ libraries were normalised against both TPR and ACTB, $24 \mathrm{~h}$ libraries genes were normalized against both $\mathrm{ACTB}$ and NM23A, and $48 \mathrm{~h}$ libraries genes were normalized against both TPR and NM23A.

\section{Statistical analysis}

Experimental data were expressed as mean \pm standard error. Statistical analyses between groups were carried out using Student's $t$-test and a $P$-value of $<0.05$ was 
considered significant. Statistical analysis was performed using the SPSS for Windows statistical package (version 16.0).

\section{Results and Discussion}

The human SHSY5Y neuroblastoma cell line has been extensively used as a neuron model in many neurobiological, neurochemical, and neurotoxicological studies [32-37]. In the present study, we investigated the effects of OA, the main DSP toxin, on gene expression of SHSY5Y cells after 3,24 and $48 \mathrm{~h}$ treatments.

\section{Identification of genes with different transcript levels in OA-exposed SHSY5Y cells}

For each exposure time 2 subtracted cDNA libraries (one forward and one reverse) were obtained. We isolated a total of 114 subtracted clones from the forward libraries (Table 2) and 133 from the reverse libraries (Table 3).

These characterized genes were associated with various functions including metabolism, signal transduction, and cytoskeleton and cell adhesion. The genes altered after the $3 \mathrm{~h}$ OA treatment were related to electron transport chain and redox homeostasis, signal transduction, metabolism, transcription, translation, cell cycle and apoptosis, and cytoskeleton and cell adhesion (Figure 1). Most of these genes are apparently involved in metabolism including electron transport chain and redox homeostasis. A few studies have previously reported the OA effects on the cell metabolism. Cable et al. [38] observed that OA affected the heme metabolism of human hepatic cell lines. Also, Shisheva and Shechter [39] showed that OA mimicked some of insulin bioeffects stimulating the glucose and lipid metabolism in rat adipocytes, and Tanti et al. [40] found that glycolysis was stimulated and glucose transport was increased after OA treatment in mouse skeletal muscle. More recently, another study showed that OA depressed the metabolic rate of rat hepatocytes and changed glucose uptake in these cells [41]. Related to electron transport chain, OA was previously found to induce alterations in mitochondrial membrane potential [42] and increased oxidative stress in the rat brain after intracerebroventricular injection [43], and in different cell types in vitro $[10,44]$. The altered expression levels in genes related to cell metabolism and electron transport chain found in this study could help to explain the effects described in all these works. Besides, $8 \%$ of the genes altered after the $3 \mathrm{~h} \mathrm{OA}$ treatment were related to cellular transport processes. OA was previously found to interfere in the secretion of newly synthesized proteins and exocytosis in rats [45]; both effects could be related to the expression alterations found in the present study.

When cells were treated with OA for $24 \mathrm{~h}$, the obtained genes were also categorized into different groups including translation, signal transduction, electron transport chain and redox homeostasis, metabolism, cell cycle and apoptosis, transcription and nuclear specific proteins, transport, and cytoskeleton and cell adhesion (Figure 2). Similar to the $3 \mathrm{~h}$ OA treatment, an important number of these genes are involved in metabolism including electron transport chain, but also a great percentage of genes related to translation were observed. The expression alterations found in the genes involved in processes of translation and transcription might be related to the previously reported OA-induced inhibition of protein synthesis $[45,46]$.

Among the genes altered after the $48 \mathrm{~h}$ OA treatment, most were related to signal transduction, translation, cell cycle and apoptosis, electron transport chain and redox homeostasis, metabolism, cytoskeleton and cell adhesion, transcription and nuclear specific proteins, and transport (Figure 3). Fewer genes related to metabolism and transcription were found altered at $48 \mathrm{~h}$, but similarly to $24 \mathrm{~h}$ an important percentage of altered genes are involved in cell cycle and apoptosis. In another previous study, the gene expression alterations in mouse BALB/c3T3 cells after different OA treatment times (from $4 \mathrm{~h}$ to 24 days, $7.8 \mathrm{ng} / \mathrm{ml}$ ) were evaluated by microarray analysis, and a total of 177 differentially expressed genes were identified [47]. The authors focused this study on the 31 genes found to be functionally involved in cell growth and/or maintenance, and observed that numerous genes associated with cell proliferation and cell cycle progression were down-regulated after OA treatment. Several genes related to apoptotic processes, some of them involved in the mitochondrial pathway of apoptosis, were also found to be altered. On the basis of their results, they concluded that multiple molecular pathways could be involved in OA-induced proliferation inhibition and apoptosis in these cells [47].

Two simple gene set enrichment analysis were performed using FatiGO tool to find which cellular KEGG pathways could be affected by OA exposure in SHSY5Y cells. The results obtained for the forward libraries revealed a total of 3 KEGG pathways altered: oocyte meiosis (hsa04114, adjusted $p$-value $=0.003$ ), Parkinson's disease (hsa05012, adjusted $p$-value $=0.035$ ), and cell cycle (hsa04110, adjusted $p$-value $=0.003)$. The genes corresponding to reverse libraries were significantly associated with KEGG pathways related to: glycolysis (hsa00010, adjusted $p$-value $=0.044$ ), oxidative phosphorylation (hsa00190, adjusted $p$-value $=0.012$ ), Vibrio cholerae infection (hsa05110, adjusted $p$-value $=$ 0.044), pathogenic Escherichia coli infection (hsa05130, adjusted $p$-value $=0.044)$, Alzheimer's disease (hsa05010, adjusted $p$-value $=0.022)$, and ribosome 
Table 2 cDNAs selected from all 3 forward SHH libraries.

\begin{tabular}{|c|c|c|c|c|}
\hline Gene name & Gene Symbol & E-value & Genebank No. & Number of genes \\
\hline $3 \mathrm{~h}$ & & & & 24 \\
\hline ATP synthase F0 subunit 6 & ATP6 & $2.00 \mathrm{E}-173$ & XM_002345305 & 1 \\
\hline $28 \mathrm{~S}$ ribosomal RNA & & $1.00 \mathrm{E}-36$ & NR_003287 & $3^{*}$ \\
\hline B-cell receptor-associated protein 31 & BCAP31 & $0.00 E+00$ & NM_005745 & 1 \\
\hline calmodulin 2 & CALM2 & $0.00 \mathrm{E}+00$ & NM_001743 & 1 \\
\hline chromosome 6 open reading frame 125 & SGA-81M & $0.00 \mathrm{E}+00$ & NM_032340 & 1 \\
\hline coiled-coil domain containing 56 & CCDC56 & $0.00 \mathrm{E}+00$ & NM_001040431 & 1 \\
\hline ferritin & FTH1 & $2.00 \mathrm{E}-30$ & NM_002032 & $2^{*}$ \\
\hline FSHD region gene 1 family, member $B$ & FRG1B & $0.00 \mathrm{E}+00$ & NR_003579 & 1 \\
\hline H2A histone family, member $\mathrm{Z}$ & $\mathrm{H} 2 \mathrm{AFZ}$ & $8.00 \mathrm{E}-153$ & NM_002106 & 1 \\
\hline $\mathrm{H} 3$ histone, family $3 \mathrm{~A}$ & $\mathrm{H} 3 \mathrm{~F} 3 \mathrm{~A}$ & 1.00E-163 & NM_002107 & 1 \\
\hline lysosomal protein transmembrane 4 alpha & LAPTM4A & $0.00 \mathrm{E}+00$ & NM_014713 & 1 \\
\hline mitochondrial ribosomal protein $L 42$ & MRPL42 & $0.00 \mathrm{E}+00$ & NM_172178 & 1 \\
\hline fascin & FSCN1 & $3.00 \mathrm{E}-29$ & AAH07539 & 1 \\
\hline nerve growth factor receptor & TNFRSF16 & $6.00 \mathrm{E}-142$ & NM_206915 & 1 \\
\hline phosphoserine phosphatase & PSPH & $2.00 \mathrm{E}-139$ & NM_004577 & 1 \\
\hline regulator of G-protein signaling 5 & RGS5 & $0.00 \mathrm{E}+00$ & NM_003617 & 1 \\
\hline small nuclear ribonucleoprotein D3 & SNRPD3 & $0.00 \mathrm{E}+00$ & NM_004175 & 1 \\
\hline superoxide dismutase 1 & SOD1 & $0.00 \mathrm{E}+00$ & NM_000454 & 1 \\
\hline SWI/SNF related, matrix associated, actin dependent regulator of chromatin & SMARCE1 & $0.00 \mathrm{E}+00$ & NM_003079 & 1 \\
\hline ubiquitin $C$ & UBC & $5.00 \mathrm{E}-39$ & NM_021009 & 1 \\
\hline Unknown genes & & & & 1 \\
\hline $24 \mathrm{~h}$ & & & & 47 \\
\hline calcyclin binding protein & CACYBP & $0.00 \mathrm{E}+00$ & NM_014412 & 1 \\
\hline $28 \mathrm{~S}$ ribosomal RNA & & $1.00 \mathrm{E}-36$ & NR_003287 & $2^{*}$ \\
\hline calmodulin 2 & CALM2 & $0.00 \mathrm{E}+00$ & NM_001743 & 1 \\
\hline casein kinase 1 & CSNK1A1 & $0.00 \mathrm{E}+00$ & NM_001892 & 1 \\
\hline chromosome 14 open reading frame 147 & SSSPTA & $9.00 \mathrm{E}-93$ & NM_138288 & 1 \\
\hline claudin domain containing 1 & CLDND1 & $0.00 \mathrm{E}+00$ & NM_019895 & 1 \\
\hline early growth response 1 & EGR1 & $0.00 \mathrm{E}+00$ & NM_001964 & 1 \\
\hline ferritin & FTL & $6.00 \mathrm{E}-161$ & NM_000146 & 1 \\
\hline glutamate-ammonia ligase (glutamine synthetase) & GLUL & $0.00 \mathrm{E}+00$ & NM_002065 & $3^{*}$ \\
\hline glyceraldehyde-3-phosphate dehydrogenase & GAPDH & $0.00 \mathrm{E}+00$ & NM_002046 & 1 \\
\hline GTP binding protein overexpressed in skeletal muscle & GEM & $0.00 \mathrm{E}+00$ & NM_181702 & $2^{*}$ \\
\hline heat shock $70 \mathrm{kDa}$ protein 8 & HSPA8 & $0.00 \mathrm{E}+00$ & NM_006597 & 1 \\
\hline heat shock protein 90 kDa alpha (cytosolic) & HSP90AA1 & $0.00 \mathrm{E}+00$ & NM_005348 & 1 \\
\hline integrator complex subunit 6 & INTS6 & $0.00 \mathrm{E}+00$ & NM_001039937 & 1 \\
\hline mab-21-like 1 & MAB21L1 & $0.00 \mathrm{E}+00$ & NM_005584 & 1 \\
\hline methionine adenosyltransferase II, beta & MAT2B & $9.00 \mathrm{E}-153$ & NM_182796 & 1 \\
\hline mitochondrial ribosomal protein $L 42$ & MRPL42 & $0.00 \mathrm{E}+00$ & NM_014050 & 1 \\
\hline NADH dehydrogenase (ubiquinone) 1 & NDUFAB1 & $0.00 \mathrm{E}+00$ & NM_005003 & 1 \\
\hline neurofilament, medium polypeptide & NEFM & $0.00 \mathrm{E}+00$ & NM_005382 & 1 \\
\hline nudix-type motif 5 & NUDT5 & $0.00 \mathrm{E}+00$ & NM_014142 & 1 \\
\hline pituitary tumor-transforming 1 & PTTG1 & $0.00 \mathrm{E}+00$ & NM_004219 & 1 \\
\hline polo-like kinase 1 & PLK1 & $5.00 \mathrm{E}-103$ & NM_005030 & 1 \\
\hline ribosomal protein L15 & RPL15 & $0.00 \mathrm{E}+00$ & NM_002948 & 1 \\
\hline ribosomal protein L23a & RPL23A & $0.00 \mathrm{E}+00$ & NM_000984 & 1 \\
\hline RNA binding motif protein 7 & RBM7 & $3.00 \mathrm{E}-111$ & NM_016090 & 1 \\
\hline shisa homolog 2 & SHISA2 & $0.00 \mathrm{E}+00$ & NM_001007538 & 1 \\
\hline cytochrome b & CYTB & $0.00 \mathrm{E}+00$ & XR_078322 & 1 \\
\hline SNF2 histone linker PHD RING helicase & SHPRH & $0.00 \mathrm{E}+00$ & NM_001042683 & 1 \\
\hline
\end{tabular}


Table 2 cDNAs selected from all 3 forward SHH libraries. (Continued)

\begin{tabular}{|c|c|c|c|c|}
\hline TAF9 RNA polymerase II, TATA box binding protein (TBP)-associated factor & TAF9 & $0.00 \mathrm{E}+00$ & NM_003187 & 1 \\
\hline Tax1 (human T-cell leukemia virus type I) binding protein 1 & TAX1BP1 & $0.00 \mathrm{E}+00$ & NM_006024 & 1 \\
\hline triosephosphate isomerase 1 & TPI1 & $0.00 \mathrm{E}+00$ & NM_000365 & $2^{*}$ \\
\hline Unknown genes & & & & 11 \\
\hline $48 \mathrm{~h}$ & & & & 43 \\
\hline actin, beta & ACTB & $0.00 \mathrm{E}+00$ & NM_001101 & 3 \\
\hline adenylate kinase domain containing 1 & AKD1 & $0.00 \mathrm{E}+00$ & NM_145025 & 1 \\
\hline ADP-ribosylation factor-like 6 interacting protein 1 & ARL6IP1 & $0.00 \mathrm{E}+00$ & NM_015161 & 1 \\
\hline CD58 molecule & CD58 & $0.00 \mathrm{E}+00$ & NR_026665 & 1 \\
\hline clusterin & CLU & $0.00 \mathrm{E}+00$ & NM_203339 & 1 \\
\hline cyclin-dependent kinase inhibitor $1 \mathrm{C}$ & CDKN1C & $0.00 \mathrm{E}+00$ & NM_000076 & 1 \\
\hline cytochrome c oxidase subunit III & MT-CO3 & $6.00 \mathrm{E}-76$ & XM_002342023 & $3^{*}$ \\
\hline family with sequence similarity 32 & FAM32A & $0.00 \mathrm{E}+00$ & NM_014077 & 1 \\
\hline ferritin & FTL & $0.00 \mathrm{E}+00$ & NM_000146 & 1 \\
\hline glutamate-ammonia ligase & GLUL & $0.00 \mathrm{E}+00$ & NM_002065 & 1 \\
\hline metallothionein $1 X$ & MT1X & $2.00 \mathrm{E}-128$ & NM_005952 & 1 \\
\hline metastasis associated lung adenocarcinoma transcript & MALAT1 & $0.00 \mathrm{E}+00$ & NR_002819 & $6^{*}$ \\
\hline microtubule-associated protein & MAPRE2 & $0.00 \mathrm{E}+00$ & NM_014268 & 1 \\
\hline M-phase phosphoprotein 8 & MPHOSPH8 & $0.00 \mathrm{E}+00$ & NM_017520 & 1 \\
\hline nudix -type motif 5 & NUDT5 & $0.00 \mathrm{E}+00$ & NM_014142 & 1 \\
\hline prostaglandin reductase 1 & PTGR1 & $0.00 \mathrm{E}+00$ & NM_012212 & 1 \\
\hline serine incorporator 3 & SERINC3 & $0.00 \mathrm{E}+00$ & NM_198941 & 1 \\
\hline cytochrome b & CYTB & $0.00 \mathrm{E}+00$ & XR_078322 & 1 \\
\hline solute carrier family 25 & SLC25A4 & $0.00 \mathrm{E}+00$ & NM_001151 & 1 \\
\hline S-phase kinase-associated protein 1 & SKP1 & $0.00 \mathrm{E}+00$ & NM_170679 & 1 \\
\hline TIMP metallopeptidase inhibitor 3 & TIMP3 & $3.00 \mathrm{E}-86$ & NM_000362 & 1 \\
\hline transcription elongation factor B (SIII) & TCEB1 & $3.00 \mathrm{E}-139$ & NM_005648 & 1 \\
\hline translocase of outer mitochondrial membrane 5 & TOMM5 & $0.00 \mathrm{E}+00$ & NM_001001790 & 1 \\
\hline tubulin, beta $2 \mathrm{C}$ & TUBB2C & $2.00 \mathrm{E}-120$ & NM_006088 & 1 \\
\hline tubulin, delta 1 & TUBD1 & $2.00 \mathrm{E}-81$ & NM_016261 & 1 \\
\hline tumor necrosis factor, alpha-induced protein 6 & TNFAIP6 & $0.00 \mathrm{E}+00$ & NM_007115 & 1 \\
\hline tyrosine 3-monooxygenase/tryptophan 5-monooxygenase activation protein & YWHAB & $8.00 \mathrm{E}-110$ & NM_003404 & 1 \\
\hline Unknown genes & & & & 7 \\
\hline
\end{tabular}

*Only one GenBank identity accession number and the highest Blastp E-value were given here because of the table capacity limitation.

(hsa03010, adjusted $p$-value $<0.001$ ). Since most effects of OA come from binding to PP1 and PP2A, a possible explanation for the altered pathways could be the protein phosphatases inhibition induced by this toxin. In fact, inhibition of PP2A by OA has been previously demonstrated to increase tau phosphorylation, a pathological hallmark of Alzheimer's disease, in SHSY5Y cells [48].

Since OA was previously reported to induce several neurotoxic effects in mammalian cells [20-23] but the underlying mechanisms are still unknown, five specific genes associated with important neuronal structures and functions such as cytoskeleton and neurotransmission, were selected to confirm their expression levels in SHSY5Y cells by real-time PCR. Results obtained from these analyses are shown in Table 4.

\section{NEFM, TUBB2A and SEPT7 expression: OA effects on} neuronal cytoskeleton

The key role of cytoskeletal organization in several important neural processes such as neurite outgrowth [49], synaptogenesis [50], structural polarity and neuronal shape [51], axonal transport [52], and neurotransmitter release [53] has been characterized. Cell shape and structural polarity are lost in neurodegenerative diseases and neural aging $[54,55]$.

OA was previously reported to induce several cytoskeleton alterations in different cell systems [56,57]. It has been hypothesized that these alterations could be due to different mechanisms that involve disruption of F-actin and /or hyperphosphorylation and activation of kinases that stimulate tight junction disassembly, but the exact molecular mechanism has not been elucidated yet [3]. 
Table 3 cDNAs selected from all 3 reverse SHH libraries.

\begin{tabular}{|c|c|c|c|c|}
\hline Gene name & Gene Symbol & E-value & Genebank No. & Number of genes \\
\hline $3 \mathrm{~h}$ & & & & 35 \\
\hline ferritin & FTL & $0.00 \mathrm{E}+00$ & NM_000146 & 1 \\
\hline phosphoglycerate kinase 1 & PGK1 & $0.00 E+00$ & NM_000291 & 1 \\
\hline SMT3 suppressor of mif two 3 homolog 2 & SUMO2 & 5.00E-115 & NM_001005849 & 1 \\
\hline ribosomal protein S14 & RPS14 & 2.00E-52 & NM_001025071 & 1 \\
\hline ATPase & ATP6V0B & 1.00E-47 & NM_001039457 & 1 \\
\hline tubulin, beta $2 \mathrm{~A}$ & TUBB2A & 2.00E-27 & NM_001069 & 1 \\
\hline actin, beta & ACTB & $0.00 \mathrm{E}+00$ & NM_001101 & 1 \\
\hline yippee-like 5 & YPEL5 & $3.00 \mathrm{E}-47$ & NM_001127401 & 1 \\
\hline translation elongation factor & EEF1A1 & $0.00 \mathrm{E}+00$ & NM_001402 & 1 \\
\hline early growth response 1 & EGR1 & $0.00 \mathrm{E}+00$ & NM_001964 & 1 \\
\hline glyceraldehyde-3-phosphate dehydrogenase & GAPDH & $0.00 \mathrm{E}+00$ & NM_002046 & 1 \\
\hline proteasome $26 \mathrm{~S}$ subunit, ATPase, 5 & PSMC5 & $0.00 \mathrm{E}+00$ & NM_002805 & 1 \\
\hline signal sequence receptor, alpha & SSR1 & 1.00E-130 & NM_003144 & 1 \\
\hline protein disulfide isomerase family A, member 6 & PDIA6 & $0.00 \mathrm{E}+00$ & NM_005742 & 1 \\
\hline malate dehydrogenase & $\mathrm{MDH} 1$ & $0.00 E+00$ & NM_005917 & $2^{*}$ \\
\hline ubiquinol-cytochrome c reductase & UQCRH & $0.00 \mathrm{E}+00$ & NM_006004 & 1 \\
\hline translocase of inner mitochondrial membrane & TIMM17A & $0.00 E+00$ & NM_006335 & 1 \\
\hline heat shock $70 \mathrm{kDa}$ protein 8 & HSPA8 & $0.00 E+00$ & NM_006597 & $2^{*}$ \\
\hline peroxiredoxin 3 & PRDX3 & $0.00 \mathrm{E}+00$ & NM_006793 & 1 \\
\hline Sec61 beta subunit & SEC61B & $0.00 \mathrm{E}+00$ & NM_006808 & 1 \\
\hline CD24 molecule & CD24 & $0.00 \mathrm{E}+00$ & NM_013230 & 1 \\
\hline striatin, calmodulin binding protein 3 & STRN3 & $0.00 \mathrm{E}+00$ & NM_014574 & 1 \\
\hline nucleolar protein 11 & NOL11 & $6.00 \mathrm{E}-158$ & NM_015462 & 1 \\
\hline cleavage and polyadenylation factor subunit & PCF11 & $0.00 \mathrm{E}+00$ & NM_015885 & 1 \\
\hline zinc finger, CCHC domain & ZCCHC17 & $3.00 \mathrm{E}-138$ & NM_016505 & 1 \\
\hline homolog 2, suppressor of mek1 & SMEK2 & $0.00 \mathrm{E}+00$ & NM_020463 & 1 \\
\hline 5-azacytidine induced 2 & $A Z I 2$ & 2.00E-161 & NM_022461 & 1 \\
\hline anaphase promoting complex subunit 13 & ANAPC13 & 2.00E-94 & NR_024401 & 1 \\
\hline cytochrome c oxidase subunit II & MT-CO2 & 4.00E-150 & XR_078889 & 1 \\
\hline NADH dehydrogenase subunit 4 & MT-ND4 & 7.00E-54 & ADG46850 & 1 \\
\hline Unknown genes & & & & 3 \\
\hline
\end{tabular}

\begin{tabular}{|c|c|c|c|c|}
\hline $24 \mathrm{~h}$ & & & & 44 \\
\hline cholinergic receptor, nicotinic, alpha 3 & CHRNA3 & $0.00 \mathrm{E}+00$ & NM_000743 & 1 \\
\hline ribosomal protein $L 3$ & RPL3 & $0.00 \mathrm{E}+00$ & NM_000967 & 1 \\
\hline ribosomal protein S6 & RPS6 & $0.00 \mathrm{E}+00$ & NM_001010 & 1 \\
\hline actin, beta & ACTB & $0.00 \mathrm{E}+00$ & NM_001101 & 1 \\
\hline casein kinase 2 & CSNK2B & 4.00E-176 & NM_001320 & 1 \\
\hline eukaryotic translation elongation factor 1 alpha 1 & EEF1A1 & $0.00 \mathrm{E}+00$ & NM_001402 & 1 \\
\hline calmodulin 2 & CALM2 & $0.00 \mathrm{E}+00$ & NM_001743 & $4^{*}$ \\
\hline septin 7 & SEPT7 & $0.00 \mathrm{E}+00$ & NM_001788 & 1 \\
\hline LIM domain only 1 (rhombotin 1) & LMO1 & $0.00 \mathrm{E}+00$ & NM_002315 & 1 \\
\hline proteasome beta type, 6 & PSMB6 & $0.00 \mathrm{E}+00$ & NM_002798 & 1 \\
\hline signal recognition particle $9 \mathrm{kDa}$ & SRP9 & $0.00 E+00$ & NM_003133 & 1 \\
\hline translocated promoter region & TPR & $0.00 \mathrm{E}+00$ & NM_003292 & 1 \\
\hline regulator of G-protein signaling 5 & RGS5 & $0.00 \mathrm{E}+00$ & NM_003617 & 1 \\
\hline NADH dehydrogenase Fe-S protein 2 & NDUFS2 & $0.00 \mathrm{E}+00$ & NM_004550 & 1 \\
\hline myeloid/lymphoid or mixed-lineage leukemia & MLLT11 & $4.00 \mathrm{E}-143$ & NM_006818 & 1 \\
\hline stathmin-like 2 & STMN2 & $0.00 \mathrm{E}+00$ & NM_007029 & 1 \\
\hline component of oligomeric golgi complex 4 & COG4 & $0.00 \mathrm{E}+00$ & NM_015386 & 1 \\
\hline RNA-binding region containing 3 & RNPC3 & $0.00 \mathrm{E}+00$ & NM_017619 & 1 \\
\hline
\end{tabular}


Table 3 cDNAs selected from all 3 reverse SHH libraries. (Continued)

\begin{tabular}{lllll}
\hline zinc finger, matrin type 5 & ZMAT5 & $0.00 \mathrm{E}+00$ & NM_019103 & 1 \\
synaptotagmin IV & SYT4 & $0.00 \mathrm{E}+00$ & NM_020783 & 2 \\
non-metastatic cells 1, protein NM23A & NM23A & $0.00 \mathrm{E}+00$ & NM_198175 & 1 \\
cytochrome c oxidase subunit III & MT-CO3 & $0.00 E+00$ & XM_002342023 & 4 \\
ATP synthase F0 subunit 6 & MT-ATP6 & $0.00 E+00$ & XM_002345305 & $4^{*}$ \\
cytochrome c oxidase subunit II & MT-CO2 & $5.00 E-149$ & XR_078889 & 7 \\
NADH dehydrogenase subunit 4 & MT-ND4 & $0.00 E+00$ & XR_078993 & 1 \\
Unknown genes & & & & 2
\end{tabular}

\begin{tabular}{|c|c|c|c|c|}
\hline $48 \mathrm{~h}$ & & & & 54 \\
\hline glutathione S-transferase & GSTP1 & $0.00 E+00$ & NM_000852 & 1 \\
\hline neuropeptide $Y$ & NPY & $0.00 \mathrm{E}+00$ & NM_000905 & 1 \\
\hline ribosomal protein $\mathrm{L} 3$ & RPL3 & 8.00E-120 & NM_000967 & $2^{*}$ \\
\hline ribosomal protein $L 4$ & RPL4 & $0.00 \mathrm{E}+00$ & NM_000968 & 1 \\
\hline ribosomal protein $L 27 a$ & RPL27A & $0.00 \mathrm{E}+00$ & NM_000990 & 1 \\
\hline ribosomal protein $L 31$ & RPL31 & 1.00E-175 & NM_000993 & 1 \\
\hline ribosomal protein $\mathbf{S 4}$ & RPS4X & $0.00 \mathrm{E}+00$ & NM_001007 & 1 \\
\hline chromosome 5 open reading frame 13 & C5orf13 & 3.00E-85 & NM_001142478 & 1 \\
\hline adenylate kinase 2 & AKA2 & 7.00E-127 & NM_001625 & 1 \\
\hline calmodulin 2 & CALM2 & $0.00 \mathrm{E}+00$ & NM_001743 & $4^{*}$ \\
\hline translation initiation factor $4 \mathrm{E}$ & EIF4E & $0.00 \mathrm{E}+00$ & NM_001968 & 1 \\
\hline lactate dehydrogenase B & LDHB & $0.00 E+00$ & NM_002300 & 1 \\
\hline NADH dehydrogenase (ubiquinone) 1 & NDUFC1 & $2.00 \mathrm{E}-100$ & NM_002494 & 1 \\
\hline signal recognition particle $9 \mathrm{kDa}$ & SRP9 & $0.00 \mathrm{E}+00$ & NM_003133 & $2^{*}$ \\
\hline regulator of G-protein signaling 5 & RGS5 & $2.00 \mathrm{E}-68$ & NM_003617 & $4^{*}$ \\
\hline DNAJC25-GNG10 readthrough transcript & DNAJC25-GNG10 & 2.00E-166 & NM_004125 & 1 \\
\hline guanine nucleotide binding protein & G protein & $0.00 \mathrm{E}+00$ & NM_004126 & 1 \\
\hline sperm associated antigen 7 & SPAG7 & $0.00 \mathrm{E}+00$ & NM_004890 & 1 \\
\hline heat shock protein $90 \mathrm{kDa}$ & HSP90AA1 & 2.00E-166 & NM_005348 & 1 \\
\hline chaperonin containing TCP1, subunit 3 & CCT3 & $0.00 \mathrm{E}+00$ & NM_005998 & 1 \\
\hline ATP synthase & ATP5L & $9.00 \mathrm{E}-140$ & NM_006476 & 1 \\
\hline mortality factor 4 like 1 & MORF4L1 & 5.00E-96 & NM_006791 & 1 \\
\hline myeloid/lymphoid or mixed-lineage leukemia & MLLT11 & $0.00 \mathrm{E}+00$ & NM_006818 & 1 \\
\hline transmembrane emp24-like trafficking protein & TMED10 & $0.00 \mathrm{E}+00$ & NM_006827 & 1 \\
\hline dickkopf homolog 1 & DKK1 & 4.00E-70 & NM_012242 & 1 \\
\hline signal peptidase complex subunit 1 & SPCS1 & $0.00 \mathrm{E}+00$ & NM_014041 & 1 \\
\hline mitochondrial ribosomal protein $L 42$ & MRPL42 & $5.00 \mathrm{E}-142$ & NM_014050 & 1 \\
\hline HIG1 hypoxia inducible domain family & HIGD1A & $0.00 \mathrm{E}+00$ & NM_014056 & 1 \\
\hline signal peptidase complex subunit 2 & SPCS2 & $0.00 \mathrm{E}+00$ & NM_014752 & 1 \\
\hline mitochondrial ribosomal protein S7 & MRPS7 & 4.00E-156 & NM_015971 & 1 \\
\hline splicing factor $3 \mathrm{~B}$ & SF3B14 & $0.00 E+00$ & NM_016047 & 1 \\
\hline hematological and neurological expressed 1 & HN1 & 5.00E-168 & NM_016185 & 1 \\
\hline transmembrane protein 9 & TMEM9 & $0.00 \mathrm{E}+00$ & NM_016456 & 1 \\
\hline chromosome 20 open reading frame 3 & APMAP & $0.00 \mathrm{E}+00$ & NM_020531 & 1 \\
\hline synaptotagmin IV & SYT4 & $0.00 E+00$ & NM_020783 & 1 \\
\hline ribosomal protein $L 41$ & RPL41 & $0.00 \mathrm{E}+00$ & NM_021104 & 1 \\
\hline transmembrane protein 167A & TMEM167A & $0.00 \mathrm{E}+00$ & NM_174909 & 1 \\
\hline tubulin, beta & TUBB & $6.00 \mathrm{E}-101$ & NM_178014 & 1 \\
\hline THAP domain containing 5 & THAP5 & $6.00 \mathrm{E}-154$ & NM_182529 & 1 \\
\hline K(lysine) acetyltransferase 5 & KAT5 & $0.00 \mathrm{E}+00$ & NM_182709 & 1 \\
\hline gonadotropin-releasing hormone & GNRHR2 & $0.00 \mathrm{E}+00$ & NR_002328 & 1 \\
\hline cytochrome c oxidase subunit II & MT-CO2 & 1.00E-151 & XR_078889 & 1 \\
\hline Unknown genes & & & & 4 \\
\hline
\end{tabular}

*Only one GenBank identity accession number and the highest Blastp E-value were given here because of the table capacity limitation. 


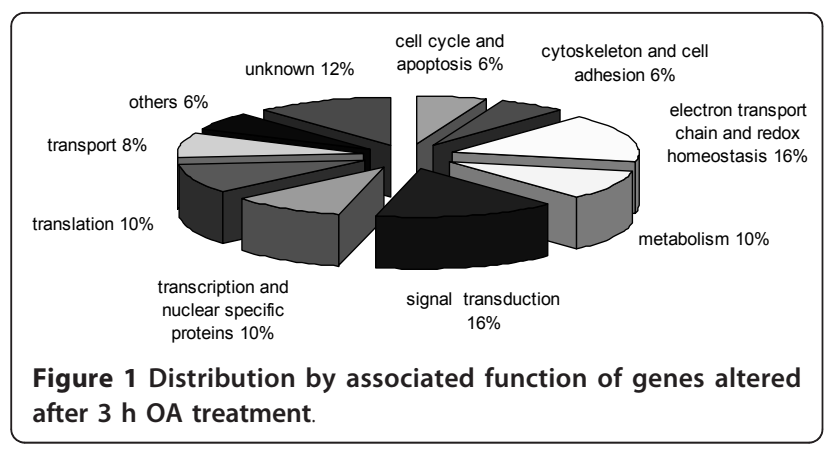

The cytoskeleton is made up of three kinds of protein filaments: actin filaments (also called microfilaments), intermediate filaments (IF) and microtubules, and other associated proteins. NEFM is the human gene which encodes for the neurofilament medium polypeptide. Neurofilaments (NEFs) are a neuron-specific type of intermediate filament proteins $(10 \mathrm{~nm}$ in diameter) found at especially high concentrations along the axons, where they regulate axonal diameter. NEFs consist of three proteins according to their molecular weight: light neurofilament (NEFL), medium neurofilament (NEFM), and heavy neurofilament (NEFH) [58]. NEFM gene is often employed as a marker of neuronal differentiation [59]. NEF protein levels are correlative to neurite outgrowth, and its gene expression is dramatically altered in neurodegenerative diseases, including Parkinson's disease and Alzheimer's disease [60]. NEF protein levels have also been suggested as a potential biomarker in organophosphorous neurotoxicity [36]. Furthermore, neurite outgrowth can be promoted by nerve growth factor (NGF) via the regulation of NEF gene expression and NEF protein phosphorylation [61]. In the present study a statistically significant underexpression of this gene was found after $3 \mathrm{~h} \mathrm{OA}$ treatment, but an overexpression was observed after $24 \mathrm{~h}$, and no effects after 48 $h$, suggesting that OA deregulates NEFM expression at the short term (within at least the first $24 \mathrm{~h}$ ), but then it stabilizes and return to control levels. It was previously described that tight coordination of the expression of neurofilament subunits is integral to the normal

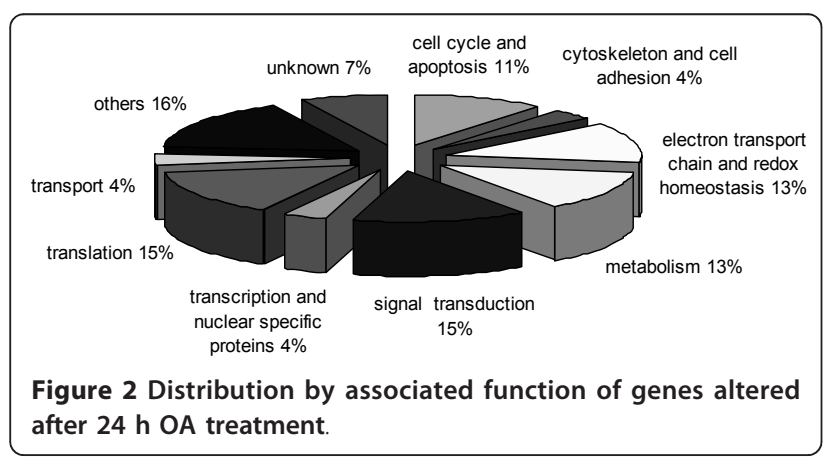

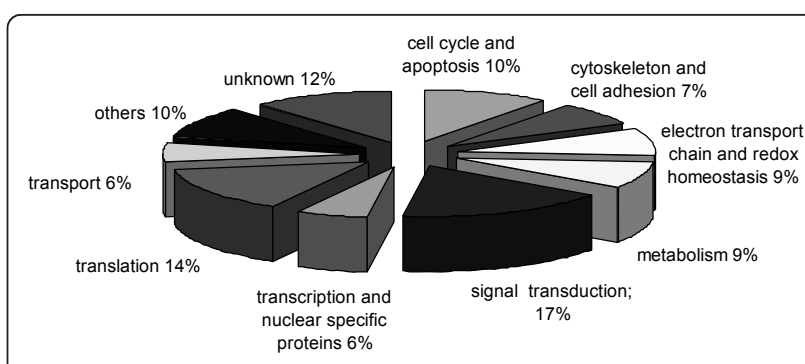

Figure 3 Distribution by associated function of genes altered after $48 \mathrm{~h} O A$ treatment.

development and function of the nervous system. Imbalances in their expression are implicated in the induction of neurodegeneration in which formation of neurofilamentous aggregates is central to the pathology [62]. To our knowledge, no studies were reported before on the expression of this gene in human neuronal cells exposed to $\mathrm{OA}$; nevertheless incubation of human fibroblasts [63] or rat brain tumour cells [64] with OA promoted the hyperphosphorylation of major intermediate filaments (IF) proteins, leading to the disassembly of IF networks, solubilisation of IF proteins, and disruption of desmosomes.

Microtubules are involved in many cellular functions, including mitosis, intracellular transport, determination of cell morphology, and differentiation [65]. In neurons, microtubules participate actively in the initial steps of neuronal polarization, the organization of intracellular compartments, the modelling of dendritic spines and

Table 4 Gene expression after real-time PCR.

\begin{tabular}{lcc}
\hline & Control & OA $(\mathbf{1 0 0} \mathbf{~ n M})$ \\
\hline NEFM & $\mathbf{3}$ h treatment \\
TUBB & $0.7 \pm 0.1$ & $0.1 \pm 0.0^{*}$ \\
SEPT7 & $1.6 \pm 0.4$ & $1.0 \pm 0.4$ \\
SYT4 & $1.7 \pm 0.4$ & $1.0 \pm 0.1^{*}$ \\
NPY & $1.4 \pm 0.0$ & $0.3 \pm 0.0^{* *}$ \\
\hline & $0.6 \pm 0.2$ & $0.3 \pm 0.0^{*}$ \\
\hline NEFM & $\mathbf{2 4}$ treatment \\
TUBB & $1.6 \pm 0.0$ & $5.6 \pm 0.6^{*}$ \\
SEPT7 & $1.5 \pm 0.1$ & $0.4 \pm 0.0^{* *}$ \\
SYT4 & $1.2 \pm 0.1$ & $0.9 \pm 0.2$ \\
NPY & $2.8 \pm 0.1$ & $0.7 \pm 0.2^{*}$ \\
\hline & $2.3 \pm 0.3$ & $1.3 \pm 0.1^{*}$ \\
\hline NEFM & $\mathbf{4 8}$ h treatment & \\
TUBB & $1.3 \pm 0.1$ & $0.8 \pm 0.3$ \\
SEPT7 & $1.3 \pm 0.1$ & $1.5 \pm 0.7$ \\
SYT4 & $0.6 \pm 0.0$ & $0.7 \pm 0.0$ \\
NPY & $0.9 \pm 0.1$ & $0.9 \pm 0.0$ \\
\hline
\end{tabular}

${ }^{*} P<0.05,{ }^{* *} P<0.01$, significant difference with regard to the expression of reference gen. 
the trafficking of cargo molecules to pre-, post- or extrasynaptic domains [66]. Tubulin, the subunit protein of microtubules, is a heterodimer, with both $\alpha$ - and $\beta$ tubulin isotypes, differing from each other in amino acid sequence [67]. In our study, the expression levels of TUBB2A, the gene encoding for the tubulin $\beta$ chain $2 \mathrm{~A}$, were analyzed in OA-treated neuronal cells. Data obtained from the real-time PCR analysis showed that this gene is down-regulated in OA-treated SHSY5Y cells at $3 \mathrm{~h}$ and $24 \mathrm{~h}$, significantly only in the second case, but at $48 \mathrm{~h}$ its expression levels were not different from the control. Microtubules were found to be altered after OA exposure in some previous studies mainly due to the hyperphosphorilation of tau, a microtubule-associated protein which promotes microtubule enlargement. Inhibition of PP2A activity by OA was suggested to produce the abnormal tau hyperphosphorylation in vivo after hippocampal injection in rats [68] and in vitro in metabolically competent brain rats [69], in mouse hippocampal HT22 cell line [70] and in human neuronal NT2N and SHSY5Y cells [48,71]. Besides, Yano et al. [56] found that OA induces reorganization of microtubules in human platelets via the phosphorylation of a microtubule-associated $90 \mathrm{kDa}$ protein, and BenitezKing et al. [72] showed that OA produces cytoskeletal disorganization and microtubule disruption in N1E-115 neuroblastoma cells, as described in other neuronal cell culture models and in rat brain [20,73,74]. TUBB2A was characterized primarily as a neuronal $\beta$-tubulin isotype [75] and possess a high expression level in brain, peripheral nerves and muscles [76]. Tubulin isotype composition may be a determinant factor on microtubule functions. Therefore, changes in expression levels of tubulin subtypes would alter the microtubule dynamics. In this sense, Falconer et al. [77] demonstrated that TUBB2 is preferentially incorporated into stable microtubules during neuronal differentiation, and Hoffman and Cleveland [78] reported that the isotype TUBB2 is polymerized more efficiently than other isotypes. The higher expression observed in several types of tumours [79] and in cancer cells resistant to microtubule-binding drugs [80] could be related with the more stability of TUBB2A isotype. The underexpression of TUBB2A observed in this work might contribute to cytoskeletal disruption effects of $\mathrm{OA}$ in a similar way, since the major isotype in neuronal cells and the more would be incorporated in a lesser extent to microtubules of SHSY5Y OA-exposed cells.

Septins are an evolutionarily conserved family of cytoskeleton GTP-binding proteins [81]. They play putative roles in cytokinesis, cellular morphogenesis, polarity determination, vesicle trafficking and apoptosis [82-85]. Septins have been identified in all eukaryotic cells. Although yeast septins are better understood, the function of mammalian septins remains largely undefined [86]. SEPT7 is a member of the septin family which is abundantly expressed in the central nervous system [81], but its functional role has not been reported yet [87]. However, a previous study showed that SEPT7 is critical for spine morphogenesis and dendrite development during neuronal maturation [87] and other study confirmed that SEPT7 directly interacts with CENP-E via the C-terminal coiled-coil region. This SEPT7-CENP-E interaction is critical for a stable CENP$\mathrm{E}$ localization to the kinetochore and for achieving chromosome alignment at the equator [88]. SEPT7 has been also related to oncogenesis. After investigating SEPT7 expression in a large number of human glioma tissue samples, Jia et al. [86] found that the expression of this gene was generally down-regulated in gliomas or even absent in some high-grade tumours. Furthermore, they showed that SEPT7 induces cell apoptosis through down-regulation of Bcl-2 and up-regulation of caspase3 , and increased cell apoptosis also contributes to the inhibitory effect of SEPT7 on glioma cell growth. Other studies showed that SEPT7 was much less expressed in brain tumours than in normal brain tissues $[81,89]$ and that neuroblastoma patients with higher SEPT7 mRNA expression might have better prognosis [90]. In our study a significant decrease in the SEPT7 expression levels were found at $3 \mathrm{~h}$, however no differences with regard to the control cells were observed after 24 or 48 h OA treatment.

Therefore, the results obtained from the genes related to cytoskeleton evaluated in this study suggest that the cytoskeleton disruption induced by OA described in previous works are due not only to the hyperphosphorylation of specific proteins caused by phosphatases inhibition, but also to short term alterations (mainly downregulation) in the expression levels of relevant genes involved in the maintenance of the cell structure as the TUBB2A, NEFM or SEPT7 genes. The fact that no effects of OA were observed after 48 h treatment in any of these genes could be related to cells ability to recover and return to their normal expression levels. However, cell viability was enormously reduced after $48 \mathrm{~h}$ OA treatment (microscopic observations). Thus, the absence of gene expression alterations found at that time might also be due to the fact that those cells intensely altered by $\mathrm{OA}$ in their gene expression at 3 and $24 \mathrm{~h}$ treatments underwent apoptosis or necrosis, being absent at $48 \mathrm{~h}$.

\section{SYT4 and NPY expression: OA effects on synaptic neurotransmission}

Synaptic neurotransmission is one of the most highly regulated of all vesicle trafficking events. Although many of the molecular components of synaptic vesicles, the presynaptic cytosol, and presynaptic plasma membrane 
have been identified, the mechanisms by which these components regulate stimulus evoked vesicle fusion and recycling are not completely understood yet. In this study, expression levels of two genes related to the neuronal signal transduction (SYT4 and NPY) after OA exposure were investigated.

The synaptotagmins (SYTs) are a family of proteins characterized by a short luminal $\mathrm{NH}_{2}$ terminus, one transmembrane region, and tandem $\mathrm{C} 2 \mathrm{~A}$ and $\mathrm{C} 2 \mathrm{~B}$ domains [91]. These synaptic proteins are also important in depolarization-induced, $\mathrm{Ca}^{2+}$-dependent fusion of the synaptic vesicles and presynaptic membrane [92]. Currently, it is thought that SYTs participate in the regulation of various steps during membrane fusion, primarily at the plasma membrane [93]. There are at least 17 SYTs isoforms that have the potential to act as modulators of membrane fusion events. SYT4 is particularly interesting since it has been found to be potentially involved in a wide variety of activities in the brain [94]; it is an immediate early gene that is up-regulated following neuronal depolarization [95] and maps to a region of human chromosome 18 associated with schizophrenia and bipolar disease [96]. Data obtained from real-time PCR showed that the SYT4 expression is inhibited by $\mathrm{OA}$ at 3 and $24 \mathrm{~h}$ exposure, but it recovers normal levels at $48 \mathrm{~h}$ treatment. In a previous study, loss of SYT4 results in a reduction of synaptic vesicles and a distortion of the Golgi structure in cultured hippocampal neurons [94]. Golgi disruptions were also found in rat pancreatic cells after OA exposure [45]. Besides, SYT4 affects a number of vesicle recycling properties in peptidergic nerve terminals in the posterior pituitary [97]. Interestingly, SYT4 also appears to play a role in the maturation of secretory granules in neuroendocrine cells [93], suggesting that it may also function in the movement of vesicles [91].

Neuropeptide Y (NPY) is a 36-amino acid peptide produced by neurons throughout the brain and by other secretor cells of the body. NPY has been associated with a number of physiological processes in the brain, including the regulation of energy balance, memory and learning, and epilepsy [98]. Similarly to SYT4, NPY expression levels after OA exposure were found to be down-regulated at 3 and $24 \mathrm{~h}$, but expression levels similar to control were observed at $48 \mathrm{~h}$. A deregulation of the hypothalamic NPY system has been proposed to be related to several pathological and pathophysiological states including cancer cachexia [99], hyperinsulinemia and hypercorticism [100], obesity and metabolic syndrome [101], and anorexia [102].

So far, no studies on SYT4 or NYP expression after OA exposure were reported, but several previous studies described neurotransmission alterations after OA exposure, and the down-regulation of genes involved in the synaptic processes found in this study could help to explain them. OA was found to inhibit mobilization of synaptic vesicles and depress $\mathrm{Ca}^{2+}$ release from sarcoplasmic reticulum in mouse neuromuscular junctions [103], to disrupt synaptic vesicle trafficking in goldfish bipolar cells [104], and to interfere with the formation of synaptic vesicle clusters in nerve terminals of frog neuromuscular junctions [105]. In vivo, OA significantly reduces electrically induced inhibitory non-adrenergic, non-cholinergic (NANC) neurotransmission responses in the rat gastric fundus, while leaving direct muscular effects of the inhibitory NANC neurotransmitters vasoactive intestinal peptide and nitric oxide unaffected, suggesting a neural site of action [106]. It was also reported that presynaptic clusters of synaptic vesicles at the frog neuromuscular junction can be disrupted by exposure to OA [105]. Furthermore, our data involving genes related to neurotransmission could also underlie the OA effects previously reported on the rodent nervous system in vivo such as hyperexcitation [107], spatial memory deficit and neurodegeneration [22] and cognitive deficits [48]. Similarly to the results obtained for the cytoskeleton genes expression, the expression levels of both SYT4 and NPY were highly depressed at 3 and $24 \mathrm{~h}$ OA exposure, but they went back to basal levels after $48 \mathrm{~h}$, suggesting that surviving cells were able to recover from OA-induced gene expression alterations.

\section{Conclusions}

To elucidate the molecular mechanisms involved in the OA-induced neurotoxic effects, $\mathrm{SSH}$ was used in SHSY5Y cells to identify genes with altered expression level at designated treatment times in the promotion stage, including an early time point $(3 \mathrm{~h})$, a middle time point $(24 \mathrm{~h})$ and a late time point $(48 \mathrm{~h})$. A total of 247 known genes were found to be altered. At $3 \mathrm{~h}$ OA treatment genes altered are mainly involved in metabolism, including electron transport chain and transcription processes. At 24 and $48 \mathrm{~h}$ OA treatments, the percentage of genes related to translation, cell cycle and apoptosis increased. The percentage of genes related to signal transduction, cytoskeleton and metabolism was in general constant at the 3 treatment times.

The data obtained from SHH were confirmed by realtime PCR for 5 specific genes associated with neuronal cytoskeleton and neurotransmission: NEFM, TUBB2A, SEPT7, SYN4, and NPY. The expression levels of the three genes involved in cytoskeleton processes (NEFM, TUBB2A and SEPT7) were found to be altered at 3 and $24 \mathrm{~h}$ OA treatments. These alterations could help to explain the previously reported cytoskeleton modifications induced by OA including cell rounding, loss of stabilization of focal adhesions, loss of barrier properties, 
and loss of cell polarity $[56,57,108-110]$. The down-regulation observed at the short term ( 3 and $24 \mathrm{~h}$ ) of the two genes participating in synaptic neurotransmission (SYT4 and NPY), might be the basis of several reported OA-induced neurotoxic effects $[22,48,107]$. No expression alterations were observed for any of the five studied genes at $48 \mathrm{~h}$ OA exposure, so surviving cells recovered their normal gene expression levels. In order to test whether current results are dependent on OA dose, similar experiments testing different OA concentrations are currently being carried out. Further investigations on the expression patterns of other relevant genes is required in order to completely understand the different effects induced by OA in these and other cells.

\section{Additional material}

Additional file 1: Single gene set enrichment analysis (KEGG pathways) of genes from forward libraries. Excel spreadsheet showing the results obtained from FatiGO analysis of the genes upregulated in SSH.

Additional file 2: Single gene set enrichment analysis (KEGG pathways) of genes from reverse libraries. Excel spreadsheet showing the results obtained from FatiGO analysis of the genes downregulated in SSH.

\section{Acknowledgements}

This work was funded by a grant from the Spanish Ministry of Science and Innovation (PSI2010-15115). V. Valdiglesias was supported by a fellowship from the University of A Coruña. Authors would like to thank the Genomics Service from INIBIC (Complejo Hospitalario Universitario A Coruña) for providing their facilities.

\section{Author details}

${ }^{1}$ Toxicology Unit, Psychobiology Department, University of A Coruña, Edificio de Servicios Centrales de Investigación, Campus Elviña s/n, 15071 A Coruña, Spain. ${ }^{2}$ Department of Cell and Molecular Biology, University of A Coruña, Faculty of Sciences, Campus A Zapateira s/n, 15071 A Coruña, Spain.

\section{Authors' contributions}

W performed the cell culture, prepared SSH libraries, carried out the sequence analyses, did the molecular work and drafted the manuscript. JFT was involved in the conceptualization, design, and implementation of all experiments; helped with the SSH libraries and molecular work and revised the manuscript. EP helped with the experiment design and drafting and revision of the manuscript. JM, the first author's (W) Ph.D. co-supervisor, was involved in the conceptualization, design, and revision of the manuscript. BL, the other first author's (W) Ph.D. co-supervisor, was involved in the conceptualization, design and implementation of experiments, and took an active part in data interpretation and writing of this manuscript. All authors read and approved the final manuscript.

Received: 15 July 2010 Accepted: 27 January 2012

Published: 27 January 2012

\section{References}

1. Tachibana K, Scheurrer PJ, Tsukitani Y, Kikuchi H, Engen DV, Clardy J, Gopichand Y, Schimitz FJ: Okadaic acid, a cytotoxicity polyether from two marine sponges of genus Halichondria. J Am Chem Soc 1981, 103.

2. Aune T, Yndestad M: Diarrhetic shellfish poisoning. In Algal Toxins in Seafood and Drinking Water. Edited by: Falconer IR. London and New York: Academic Press; 1993:87-104.
3. Vale C, Botana LM: Marine toxins and the cytoskeleton: okadaic acid and dinophysistoxins. FEBS J 2008, 275:6060-6066.

4. Fujiki H, Suganuma M, Suguri H, Yoshizawa S, Takagi K, Uda N, Wakamatsu K, Yamada K, Murata M, Yasumoto T, et al: Diarrhetic shellfish toxin, dinophysistoxin-1, is a potent tumor promoter on mouse skin. Jpn J Cancer Res 1988, 79:1089-1093.

5. Suganuma M, Fujiki H, Suguiri $H$, Yoshizwa $S$, Hirota M, Nakayasu M, Ojika M, Wakamatsu K, Yamada K, Sugimura T: Okadaic acid: an additional non-phorbol-12-tetrade-canoate-13-acetate type tumour promoter. Proc Natl Acad Sci USA 1988, 85:1768-1771.

6. Le Hegarat L, Puech L, Fessard V, Poul JM, Dragacci S: Aneugenic potential of okadaic acid revealed by the micronucleus assay combined with the FISH technique in CHO-K1 cells. Mutagenesis 2003, 18:293-298.

7. Carvalho PS, Catian R, Moukha S, Matias WG, Creppy EE: Comparative study of domoic acid and okadaic acid induced-chromosomal abnormalities in the Caco-2 cell line. Int J Environ Res Public Health 2006, 3:4-10.

8. Valdiglesias V, Laffon B, Pásaro E, Méndez J: Evaluation of okadaic acidinduced genotoxicity in human cells using the micronucleus test and YH2AX analysis. J Toxicol Environ Health A 2011, 74:980-992.

9. Fessard V, Grosse Y, Pfohl-Leszkowicz A, Puiseux-Dao S: Okadaic acid treatment induces DNA adduct formation in BHK21 C13 fibroblasts and HESV keratinocytes. Mutat Res 1996, 361:133-141.

10. Valdiglesias V, Laffon B, Pásaro E, Cemeli E, Anderson D, Méndez J: Induction of oxidative damage by the marine toxin okadaic acid depends on human cell type. Toxicon 2011, 57:882-888.

11. Valdiglesias V, Méndez J, Pásaro E, Cemeli E, Anderson D, Laffon B: Assessment of okadaic acid effects on cytotoxicity, DNA damage and DNA repair in human cells. Mutat Res 2010, 689:74-79.

12. Van Dolah FM, Ramsdell JS: Okadaic acid inhibits a protein phosphatase activity involved in formation of the mitotic spindle of GH4 rat pituitary cells. J Cell Physiol 1992, 152:190-198.

13. Ghosh S, Paweletz N, Schroeter D: Effects of okadaic acid on mitotic HeLa cells. J Cell Sci 1992, 103:117-124.

14. Rajesh D, Schell K, Verma AK: Ras mutation, irrespective of cell type and p53 status, determines a cell's destiny to undergo apoptosis by okadaic acid, an inhibitor of protein phosphatase 1 and 2A. Mol Pharmacol 1999, 56:515-525.

15. Valdiglesias $V$, Laffon B, Pásaro E, Méndez J: Okadaic acid induces morphological changes, apoptosis and cell cycle alterations in different human cell types. J Environ Monit 2011, 13:1831-1840,

16. Lerga A, Richard C, Delgado MD, Canelles M, Frade P, Cuadrado MA, Leon J: Apoptosis and mitotic arrest are two independent effects of the protein phosphatases inhibitor okadaic acid in K562 leukemia cells. Biochem Biophys Res Commun 1999, 260:256-264.

17. Casarini L, Franchini A, Malagoli D, Ottaviani E: Evaluation of the effects of the marine toxin okadaic acid by using FETAX assay. Toxicol Lett 2007, 169:145-151.

18. Ehlers A, Stempin S, Al-Hamwi R, Lampen A: Embryotoxic effects of the marine biotoxin okadaic acid on murine embryonic stem cells. Toxicon 2010, 55:855-863.

19. FAO (Food and Agriculture Organization): Marine Biotoxins. FAO Food and Nutritrion Paper 80 Rome: Food and Agriculture Organization of the United Nations; 2004

20. Arias C, Sharma N, Davies P, Shafit-Zagardo B: Okadaic acid induces early changes in microtubule-associated protein 2 and tau phosphorylation prior to neurodegeneration in cultured cortical neurons. J Neurochem 1993, 61:673-682.

21. Nuydens R, de Jong M, Van Den Kieboom G, Heers C, Dispersyn G, Cornelissen F, Nuyens R, Borgers M, Geerts H: Okadaic acid-induced apoptosis in neuronal cells: evidence for an abortive mitotic attempt. $J$ Neurochem 1998, 70:1124-1133.

22. He J, Yamada K, Zou LB, Nabeshima T: Spatial memory deficit and neurodegeneration induced by the direct injection of okadaic acid into the hippocampus in rats. J Neural Transm 2001, 108:1435-1443.

23. Zhang Z, Simpkins JW: Okadaic acid induces cognitive deficiency in rats. Society for Neuroscience 2008, Abstract No. 556.4/BB25.

24. Bialojan C, Takai A: Inhibitory effect of a marine-sponge toxin, okadaic acid, on protein phosphatases. Specificity and kinetics. Biochem J 1988, 256:283-290.

25. Traoré A, Baudrimont I, Dano S, Sanni A, Larondelle Y, Schneider YJ, Creppy EE: Epigenetic properties of the diarrhetic marine toxin okadaic 
acid: inhibition of the gap junctional intercellular communication in a human intestine epithelial cell line. Arch Toxicol 2003, 77:657-662.

26. Sheppeck JEl, Gauss CM, Chamberlin AR: Inhibition of the Ser-Thr phosphatases PP1 and PP2A by naturally occurring toxins. Bioorg Med Chem 1997, 5:1739-1750.

27. Schröder HC, Breter HJ, Fattorusso E, Ushijima H, Wiens M, Steffen R, Batel R, Müller WE: Okadaic acid, an apoptogenic toxin for symbiotic/ parasitic annelids in the demosponge Suberites domuncula. Appl Environ Microbiol 2006, 72:4907-4916.

28. Sugiyama N, Konoki K, Tachibana K: Isolation and characterization of okadaic acid binding proteins from the marine sponge Halichondria okadai. Biochemistry 2007, 46:11410-11420.

29. Hillmann A, Dunne E, Kenny D: CDNA Amplification by SMART-PCR and Suppression Subtractive Hybridization (SSH)-PCR. In DNA and RNA Profiling in Human Blood: Methods and Protocols Edited by: Peter Bugert 2009, 496:223-243

30. Hellemans J, Mortier G, De Paepe A, Speleman F, Vandesompele J: qBase relative quantification framework and software management and automated analysis of real-time quantitative PCR data. Genome Biol 2007, 8:R19.

31. Vandesompele J, De Preter K, Pattyn F, Poppe B, Van Roy N, De Paepe A, Speleman F: Accurate normalization of real-time quantitative RT-PCR data by genomic averaging of multiple control genes. Genome Biol 2002, 3, Research0034.

32. Encinas $\mathrm{M}$, Iglesias $\mathrm{M}$, Llecha $\mathrm{N}$, Comella JX: Extracellular-regulated kinases and phosphatidylinositol 3-kinase are involved in brain-derived neurotrophic factor-mediated survival and neuritogenesis of the neuroblastoma cell line SH-SY5Y. J Neurochem 1999, 73:1409-1421.

33. Gomez-Santos C, Ferrer I, Reiriz J, Vinals F, Barrachina M, Ambrosio S: MPP+ increases alpha-synuclein expression and ERK/MAP-kinase phosphorylation in human neuroblastoma SH-SY5Y cells. Brain Res 2002, 935:32-39.

34. Hasegawa T, Matsuzaki M, Takeda A, Kikuchi A, Furukawa K, Shibahara S, Itoyama Y: Increased dopamine and its metabolites in SH-SY5Y neuroblastoma cells that express tyrosinase. J Neurochem 2003, 87:470-475.

35. Hong MS, Hong SJ, Barhoumi R, Burghardt RC, Donnelly KC, Wild JR, Venkatraj $\mathrm{V}$, Tiffany-Castiglioni E: Neurotoxicity induced in differentiated SK-N-SH-SY5Y human neuroblastoma cells by organophosphorus compounds. Toxicol Appl Pharmacol 2003, 186:110-118.

36. Cho T, Tiffany-Castiglioni E: Neurofilament 200 as an indicator of differences between mipafox and paraoxon sensitivity in SY5Y neuroblastoma cells. J Toxicol Environ Health A 2004, 67:987-1000.

37. Di Daniel E, Mudge AW, Maycox PR: Comparative analysis of the effects of four mood stabilizers in SH-SY5Y cells and in primary neurons. Bipolar Disord 2005, 7:33-41.

38. Cable EE, Kuhn BR, Isom HC: Effects of modulators of protein phosphorylation on heme metabolism in human hepatic cells: induction of delta-aminolevulinic synthase mRNA and protein by okadaic acid. DNA Cell Biol 2002, 21:323-332.

39. Shisheva A, Shechter Y: Effect of okadaic acid in rat adipocytes: differential stimulation of glucose and lipid metabolism and induction of refractoriness to insulin and vanadate. Endocrinology 1991, 129:2279-2288.

40. Tanti JF, Grémeaux T, Van Obberghen E, Le Marchand-Brustel Y: Effects of okadaic acid, an inhibitor of protein phosphatases- 1 and $-2 \mathrm{~A}$, on glucose transport and metabolism in skeletal muscle. J Biol Chem 1991, 266:2099-2103.

41. Espiña B, Louzao MC, Cagide E, Alfonso A, Vieytes MR, Yasumoto T, Botana LM: The methyl ester of okadaic acid is more potent than okadaic acid in disrupting the actin cytoskeleton and metabolism of primary cultured hepatocytes. Br J Pharmacol 2010, 159:337-344.

42. Lago J, Santaclara F, Vieites JM, Cabado AG: Collapse of mitochondrial membrane potential and caspases activation are early events in okadaic acid-treated Caco-2 cells. Toxicon 2005, 46:579-586.

43. Túnez JA, Druker-Colín R, Muñoz MC, Montilla P: Cytoprotection by melatonin, precursors and metabolites in an in vitro model of neurotoxicity induced by okadaic acid. Lett Durg Design Discov 2005, 2:316-321
44. Ferrero-Gutiérrez A, Pérez-Gómez A, Novelli A, Fernández-Sánchez MT: Inhibition of protein phosphatases impairs the ability of astrocytes to detoxify hydrogen peroxide. Free Rad Biol Med 2008, 44:1806-1816.

45. Waschulewski IH, Kruse ML, Agricola B, Kern HF, Schmidt WE: Okadaic acid disrupts Golgi structure and impairs enzyme synthesis and secretion in the rat pancreas. Am J Physiol 1996, 270:G939-947.

46. Matias WG, Bonini M, Creppy EE: Inhibition of protein synthesis in a cellfree system and Vero cells by okadaic acid, a diarrhetic shellfish toxin. J Toxicol Environ Health 1996, 48:309-317.

47. Ao L, Liu JY, Gao LH, Liu SX, Yang MS, Huang MH, Cao J: Differential expression of genes associated with cell proliferation and apoptosis induced by okadaic acid during the transformation process of BALB/C 3T3 cells. Toxicol In Vitro 2008, 22:116-127.

48. Zhang Z, Simpkins JW: Okadaic acid induces tau phosphorylation in SH-SY5Y cells in an estrogen-preventable manner. Brain Res 2010, 1345:176-181.

49. Mattson MP: Neurotransmitters in the regulation of neuronal cytoarchitecture. Brain Res Rev 1988, 13:179-212.

50. Vega IE, Hsu SC: The exocyst complex associates with microtubules to mediate vesicle targeting and neurite outgrowth. J Neurosci 2001, 21:3839-3848.

51. Cid-Arregui A, De Hoop M, Dotti CG: Mechanism of neuronal polarity. Neurobiol Aging 1995, 16:239-243.

52. Reinsch SS, Mitchison TJ, Kirschner M: Microtubule polymer assembly and transport during axonal elongation. J Cell Biol 1991, 115:365-379.

53. Trifaro JM, Vitale ML: Cytoskeleton dynamics during neurotransmitter release. Trends Neurosci 1993, 16:466-472.

54. Nakamura S, Akiguchi I, Kameyama M, Mizuno N: Age-related changes of pyramidal cell basal dendrites in layers III and V of human motor cortex: a quantitative Golgi study. Acta Neuropathol (Berl.) 1985, 65:281-284.

55. Kowall NW, Kosik KS: Axonal disruption and aberrant localization of tau protein characterize the neuropil pathology of Alzheimer's disease. Ann Neurol 1987, 22:639-643.

56. Yano Y, Sakon M, Kambayashi J, Kawasaki T, Senda T, Tanaka K, Yamada F, Shibata N: Cytoskeletal reorganization of human platelets induced by the protein phosphatase 1/2 A inhibitors okadaic acid and calyculin A. Biochem J 1995, 307:439-449.

57. Cabado AG, Leira F, Vieytes MR, Vieites JM, Botana LM: Cytoskeletal disruption is the key factor that triggers apoptosis in okadaic acidtreated neuroblastoma cells. Arch Toxicol 2004, 78:74-85.

58. Qian Y, Zheng Y, Tiffany-Castiglioni E: Valproate reversibly reduces neurite outgrowth by human SY5Y neuroblastoma cells. Brain Res 2009, 1302:21-33.

59. Hofsli E, Wheeler TE, Langaas M, Lægreid A, Thommesen L: Identification of novel neuroendocrine-specific tumour genes. Br J Cancer 2008, 99:1330-1339.

60. Al-Chalabi A, MilleR CC: Neurofilaments and neurological disease. Bioessays 2003, 25:346-355.

61. Lindenbaum MH, Carbonetto S, Grosveld F, Flavell D, Mushynski WE: Transcriptional and post-transcriptional effects of nerve growth factor on expression of the three neurofilament subunits in PC-12 cells. J Biol Chem 1988, 263:5662-5667.

62. Thyagarajan M, Strong MJ, Szaro BJ: Post-transcriptional control of neurofilaments in development and disease. Experim Cell Res 2007, 313:2088-2097.

63. Yatsunami J, Fujiki H, Suganuma M, Yoshizawa S, Eriksson JE, Olson MO, Goldman RD: Vimentin is hyperphosphorylated in primary human fibroblasts treated with okadaic acid. Biochem Biophys Res Commun 1991, 177:1165-1170.

64. Lee WC, Yu JS, Yang SD, Lai YK: Reversible hyperphosphorylation and reorganization of vimentin intermediate filaments by okadaic acid in $9 \mathrm{~L}$ rat brain tumor cells. J Cell Biochem 1992, 49:378-393.

65. Howard J, Hyman AA: Dynamics and mechanics of the microtubule plus end. Nature 2003, 422:753-758.

66. Janke C, Kneusse M: Tubulin post-translational modifications: encoding functions on the neuronal microtubule cytoskeleton. Trends Neurosci 2010, 33:362-372.

67. Guo F, An T, Rein KS: The algal hepatotoxin okadaic acid is a substrate for human cytochromes CYP3A4 and CYP3A5. Toxicon 2010, 55:325-332. 
68. Yin YY, Liu H, Cong XB, Liu Z, Wang Q, Wang JZ, Zhu LQ: Acetyl-L-carnitine attenuates okadaic acid induced tau hyperphosphorylation and spatial memory impairment in rats. J Alzheimers Dis 2010, 19:735-746.

69. Gong CX, Lidsky T, Wegiel J, Zuck L, Grundke-lqbal I, lqbal K: Phosphorylation of microtubule-associated protein tau is regulated by protein phosphatase $2 \mathrm{~A}$ in mammalian brain. Implications for neurofibrillary degeneration in Alzheimer's disease. J Biol Chem 2000, 275:5535-5544

70. Poppek D, Keck S, Ermak G, Jung T, Stolzing A, Ullrich O, Davies KJA, Grune T: Phosphorylation inhibits turnover of the tau protein by the proteasome: influence of RCAN1 and oxidative stress. Biochem J 2006, 400:511-520

71. Merrick SE, Trojanowski JQ, Lee VM: Selective destruction of stable microtubules and axons by inhibitors of protein serine/threonine phosphatases in cultured human neurons. J Neurosci 1997, 17:5726-5737

72. Benitez-King G, Túnez I, Bellon A, Ortíz GG, Antón-Tay F: Melatonin prevents cytoskeletal alterations and oxidative stress induced by okadaic acid in N1E-115 cells. Experim Neurol 2003, 182:151-159.

73. Arendt T, Holzer M, Fruth R, Burckner MK, Gartner U: Paired helical filament-like phosphorylation of tau, deposition of beta/A4-amyloid and memory impairment in rat induced by chronic inhibition of phosphatase 1 and 2A. Neuroscience 1995, 69:691-698.

74. Kim D, Su J, Cotman CW: Sequence of neurodegeneration and accumulation of phosphorylated tau in cultured neurons after okadaic treatment. Brain Res 1999, 839:253-262.

75. Sullivan KF, Cleveland DW: Identification of conserved isotype-defining variable region sequences for four vertebrate beta tubulin polypeptide classes. Proc Natl Acad Sci USA 1986, 83:4327-4331.

76. Katsetos $C D$, Dráberová E, Legido A, Dumontet $C$, Dráber P: Tubulin targets in the pathobiology and therapy of glioblastoma multiforme. I. Class III beta-tubulin. J Cell Physiol 2009, 221:505-513.

77. Falconer MM, Echeverri CJ, Brown DL: Differential sorting of beta tubulin isoptypes into colchicine-stable microtubules during neuronal and muscle differentiation of embryonal carcinoma cells. Cell Motil Cytoskeleton 1992, 21:313-325

78. Hoffman PN, Cleveland DW: Nrurofilament and tubulin expression recapitulates the development program during axonal regeneration: induction of a specific beta-tubulin isotype. Proc Natl Acad Sci USA 1988, 85:4530-4533.

79. Yeh IT, Luduena RF: The betall isotype of tubulin is present in the cell nuclei of a variety of cancers. Cell Motil Cytoskleton 2004, 57:96-106.

80. Estève MA, Carré $m$, Bourgarel-Rey V, Kruczynski A, Raspaglio G, Ferlini $C$, Braguer D: Bcl-2 down-regulation and tubulin subtype composition are involved in resistance of ovarian cancer cells to vinflunine. Mol Cancer Ther 2005, 5:2824-2833.

81. Hall PA, Jung K, Hillan KJ, Russell SE: Expression profilingthe human septin gene family. J Pathol 2005, 206:269-278.

82. Beites $\mathrm{CL}$, Xie H, Bowser R, Trimble WS: The septin CDCrel-1 binds syntaxin and inhibits exocytosis. Nat Neurosci 1999, 2:434-439.

83. Field CM, Kellogg D: Septins: cytoskeletal polymers or signalling GTPases? Trends Cell Biol 1999, 9:387-394.

84. Larisch S, Yi Y, Lotan R, Kerner H, Eimerl S, Tony Parks W, Gottfried Y, Birkey Reffey S, de Caestecker MP, Danielpour D, Book-Melamed N, Timberg R, Duckett CS, et al: A novel mitochondrial septin-like protein, ARTS, mediates apoptosis dependent on its P-loop motif. Nat Cell Biol 2000, 2:915-921.

85. Kartmann B, Roth D: Novel roles for mammalian septins: from vesicle trafficking to oncogenesis. J Cell Sci 2001, 114:839-844.

86. Jia ZF, Huang Q, Kang CS, Yang WD, Wang GX, Yu SZ, Jiang H, Pu PY: Overexpression of septin 7 suppresses glioma cell growth. J Neurooncol 2010, 98:329-340.

87. Tada T, Simonetta A, Batterton M, Kinoshita M, Edbauer D, Sheng M: Role of septin cytoskeleton in spine morphogenesis and dendrite development in neurons. Curr Biol 2007, 17:1752-1758.

88. Zhu M, Wang F, Yan F, Yao PY, Du J, Gao X, Wang X, Wu Q, Ward T, Li J, Kioko S, Hu R, Xie W, Ding X, Yao X: Septin 7 Interacts with Centromereassociated Protein E and Is Required for Its Kinetochore Localization. J Biol Chem 2008, 283:18916-18925.

89. Xu S, Jia ZF, Huang Q, Kang C, Wang GX, Zhang AL, Liu XZ, Zhou X, Xu P, Pu PY: Study on the anti-invasion effect of SEPT7 gene for U251MG glioma cell in vitro. Zhonghua Yi Xue Yi Chuan Xue Za Zhi 2008, 25:262-267.

90. Nagata T, Takahashi Y, Asai S, Ishii Y, Mugishima H, Suzuki T, Chin M Harada K, Koshinaga S, Ishikawa K: The high level of hCDC10 gene expression in neuroblastoma may be associated with favorable characteristics of the tumor. J Surg Res 2000, 92:267-275.

91. Bai J, Chapman ER: The C2 domains of synaptotagmin-partners in exocytosis. Trends Biochem Sci 2004, 29:143-151.

92. Machado HB, Liu W, Vician LJ, Herschman HR: Synaptotagmin IV overexpression inhibits depolarization-induced exocytosis in PC12 cells. J Neurosci Res 2004, 76:334-341.

93. Ahras M, Otto GP, Tooze SA: Synaptotagmin IV is necessary for the maturation of secretory granules in PC12 cells. J Cell Biol 2006, 173:241-251.

94. Arthur CP, Dean C, Pagratis M, Chapman ER, Stowell MHB: Loss of synaptotagmin iv results in a reduction in synaptic vesicles and a distortion of the golgi structure in cultured hippocampal neurons. Neuroscience 2010, 167:135-142.

95. Vician L, Lim IK, Ferguson G, Tocco G, Baudry M, Herschman HR: Synaptotagmin IV is an immediate early gene induced by depolarization in PC12 cells and in brain. Proc Natl Acad Sci USA 1995, 92:2164-2168.

96. Ferguson GD, Vician L, Herschman HR: Synaptotagmin IV: biochemistry, genetics, behavior, and possible links to human psychiatric disease. $\mathrm{Mol}$ Neurobiol 2001, 23:173-185

97. Zhang Z, Bhalla A, Dean C, Chapman ER, Jackson MB: Synaptotagmin IV: a multifunctional regulator of peptidergic nerve terminals. Nat Neurosci 2009, 12:163-171.

98. Colmers WF, El Bahh B: Neuropeptide Y and Epilepsy. Epilepsy Currents 2003, 3:53-58.

99. King PJ, Williams G: Role of ARC NPY neurons in energy balance. Drug News Perspect 1998, 11:402-410.

100. Rohner-Jeanrenaud $E$, Jeanrenaud B: Central nervous system and body weight regulation. Ann Endocrinol 1997, 58:137-142.

101. Kuo HW, Chou SY, Hu TW, Wu FY, Chen DJ: Urinary 8-hydroxy-2'deoxyguanosine $(8-\mathrm{OHdG})$ and genetic polymorphisms in breast cancer patients. Mutat Res 2007, 631:62-68

102. Kaye WH, Berrettini W, Gwirtsman H, George DT: Altered cerebrospinal fluid neuropeptide $Y$ and peptide $Y Y$ immunoreactivity in anorexia and bulimia nervosa. Arch Gen Psychiatry 1990, 47:548-56.

103. Hong SJ: Inhibition of mouse neuromuscular transmission and contractile function by okadaic acid and cantharidin. $\mathrm{Br} J$ Pharmacol 2000, 130:1211-1218.

104. Guatimosim C, Hull C, Von Gersdorff H, Prado MA: Okadaic acid disrupts synaptic vesicle trafficking in a ribbon-type synapse. J Neurochem 2002, 82:1047-1057.

105. Betz WJ, Henkel KW: Okadaic acid disrupts clusters of synaptic vesicles in frog motor nerve terminals. J Cell Biol 1994, 124:843-854

106. Storr M, Folmer R, Kurjak M, Schusdziarra V, Allescher HD: Okadaic acid inhibits relaxant neural transmission in rat gastric fundus in vitro. Acta Physiol Scand 2002, 175:29-36.

107. Arias C, Sharma N, Davies P, Shafit-Zagardo B: Okadaic acid induces early changes in microtubule-associated protein 2 and tau phosphorylation prior to neurodegeneration in cultured cortical neurons. J Neurochem $1998,61: 673-682$.

108. Tripuraneni J, Koutsouris A, Pestic L, De Lanerolle P, Hecht G: The toxin of diarrheic shellfish poisoning, okadaic acid, increases intestinal epithelial paracellular permeability. Gastroenterology 1997, 112:100-108.

109. Niggli V, Djafarzadeh S, Keller H: Stimulusinduced selective association of actin-associated proteins (alpha-actinin) and protein kinase $\mathrm{C}$ isoforms with the cytoskeleton of human neutrophils. Exp Cell Res 1999, 250:558-568.

110. Romashko AA, Young MR: Protein phosphatase-2A maintains focal adhesion complexes in keratinocytes and the loss of this regulation in squamous cell carcinomas. Clin Exp Metastasis 2004, 21:371-379.

doi:10.1186/1471-2164-13-46

Cite this article as: Valdiglesias et al:: Identification of differentially expressed genes in SHSY5Y cells exposed to okadaic acid by suppression subtractive hybridization. BMC Genomics 2012 13:46. 